\title{
Delayed Neuronal Death in the CA1 Pyramidal Cell Layer of the Gerbil Hippocampus following Transient Ischemia Is Apoptosis
}

\author{
Tohru Nitatori,' Noboru Sato,' Satoshi Waguri, ${ }^{1}$ Yasuko Karasawa, ${ }^{2}$ Hiroaki Araki,, Kazuo Shibanai,' Eiki \\ Kominami, ${ }^{3}$ and Yasuo Uchiyama ${ }^{1}$ \\ 'Department of Cell Biology and Neuroanatomy, Iwate Medical University School of Medicine, Morioka 020, Iwate-Ken, \\ Japan, '2Department of Pharmacology, Research Center, Taisho Pharmaceutical Co., Ltd., 1-403 Yoshinocho, Ohmiya 330, \\ Saitama-Ken, Japan, and ${ }^{3}$ Department of Biochemistry, Juntendo University School of Medicine, Hongoh, Bunkyou-ku \\ 113, Tokyo, Japan
}

The CA1 pyramidal neurons in the hippocampus are selectively vulnerable to transient ischemic damage. In experimental animals, the CA1 pyramidal neurons undergo cell death several days after brief forebrain ischemia. It remains, however, unknown whether this delayed neuronal death is necrosis or apoptosis. To investigate the degenerating processes of the CA1 pyramidal neurons in gerbil hippocampus after brief ischemia, lysosomal and nuclear alterations in the cells were examined using immunocytochemistry, in situ nickend labeling, and Southern blotting. By light and electron microscopy, immunoreactivity for cathepsins $B, H$, and $L$, representative lysosomal cysteine proteinases, increased in the CA1 pyramidal neurons $3 \mathrm{~d}$ after ischemic insult, which showed cell shrinkage. By morphometric analysis, the volume density of cathepsin B-positive lysosomes markedly increased $\mathbf{3} \mathbf{d}$ after ischemic insult, while that of autophagic vacuole-like structures also increased at this stage, suggesting that cathepsin B-immunopositive lysosomes increasing in the neurons after ischemic insult are mostly autolysosomes. Nuclei of the CA1 neurons were nick-end labeled by biotinylated dUTP mediated by terminal deoxytransferase 3 and $4 \mathrm{~d}$ after ischemic insult, but not in the prior stages. Simultaneously, dense chromatin masses appeared in nuclei of the neurons. By Southern blotting, laddering of DNA occurred only in CA1 hippocampal tissues obtained $4 \mathrm{~d}$ after ischemic insult. Confocal laser scanning microscopy demonstrated that the fragmented DNA in the CA 1 pyramidal layer was phagocytosed by microglial cells. The results suggest that delayed death of the CA1 pyramidal neurons after brief ischemia is not necrotic but apoptotic.

[Key words: Mongolian gerbil, hippocampus, brief cerebral ischemia, autolysosomes, cysteine proteinases, DNA fragmentation, apoptosis]

The CA1 pyramidal neurons in the hippocampus have been shown to undergo selective cell death both in experimental animals and in humans after ischemic insult (Ito et al., 1975;

\footnotetext{
Received May 10, 1994; revised June 28, 1994; accepted Aug. 2, 1994.

This article was supported by a Grant-in-Aid for Scientific Research on Priority Areas, Ministry of Education, Science and Culture, Japan, and by a Grand from Keiryoukai Research Foundation (no. 44).

Correspondence should be addressed to Dr. Yasuo Uchiyama at the above address.

Copyright (C) 1995 Society for Neuroscience $0270-6474 / 95 / 151001-11 \$ 05.00 / 0$
}

Pulsinelli and Brierley et al., 1979; Kirino, 1982; Kirino and Sano, 1984; Petito et al., 1987; Bonnekoh et al., 1990). Neuronal cell death, however, does not occur soon after ischemic insult, but the neurons survive several days. Physiological as well as biochemical analyses using animal models have demonstrated that the CA1 pyramidal neurons are normal $24 \mathrm{hr}$ after brief forebrain ischemia (Suzuki et al., 1983a,b; Arai et al., 1986; Monmaur et al., 1986). The CAl pyramidal neurons of gerbil hippocampus degenerate within 2 to $4 \mathrm{~d}$ after transient ischemia (Petito et al., 1987) and only $5.8 \%$ of the neurons survive 3 weeks later (Bonnekoh et al., 1990).

There has been no evidence whether this delayed neuronal death is necrosis or apoptosis. According to the morphological criteria of apoptosis, dying cells show chromatin condensation and cell shrinkage, followed by heterophagocytosis (Kerr et al., 1987; Clarke, 1990). Until the present, no study has reported that chromatin condensation appears in nuclei of the CAl pyramidal neurons after ischemic impact. Microglial cells, however, invade the CA1 pyramidal layer, when the pyramidal neurons degenerate (Kirino and Sano, 1984). Moreover, in the course of the study on the delayed death of the CAl pyramidal neurons after transient ischemia, we noticed that shrinkage of these neurons suddenly occurs 3 or $4 \mathrm{~d}$ after ischemic insult. These results suggest the possibility that delayed death of the CAl pyramidal neurons after brief ischemia is not necrotic but apoptotic.

To determine whether the delayed neuronal death occurring in the CAl pyramidal layer of gerbil hippocampus after brief ischemia is necrotic or apoptotic, we investigated the dying processes of CA1 pyramidal neurons with respect to cell shrinkage and nuclear changes. To detect the cytoplasmic changes, we immunocytochemically examined alterations in lysosomes, which have been shown to participate in the dying processes of some embryonic cells by forming autolysosomes (Clarke, 1990). Moreover, to detect nuclear changes, in situ nick-end labeling of biotinylated dUTP mediated by terminal deoxytransferase (TUNEL reaction) and Southern blot analysis were applied to the tissue. Participation of microglial cells in the degenerative processes of the CA1 neurons was also examined by specific staining of microglia.

\section{Materials and Methods}

Animals

Ninety-seven adult male Mongolian gerbils (12 weeks of age, ca. 70 $100 \mathrm{gm}$ ) were used: 15 animals for the control group and the rest for the experimental groups. 

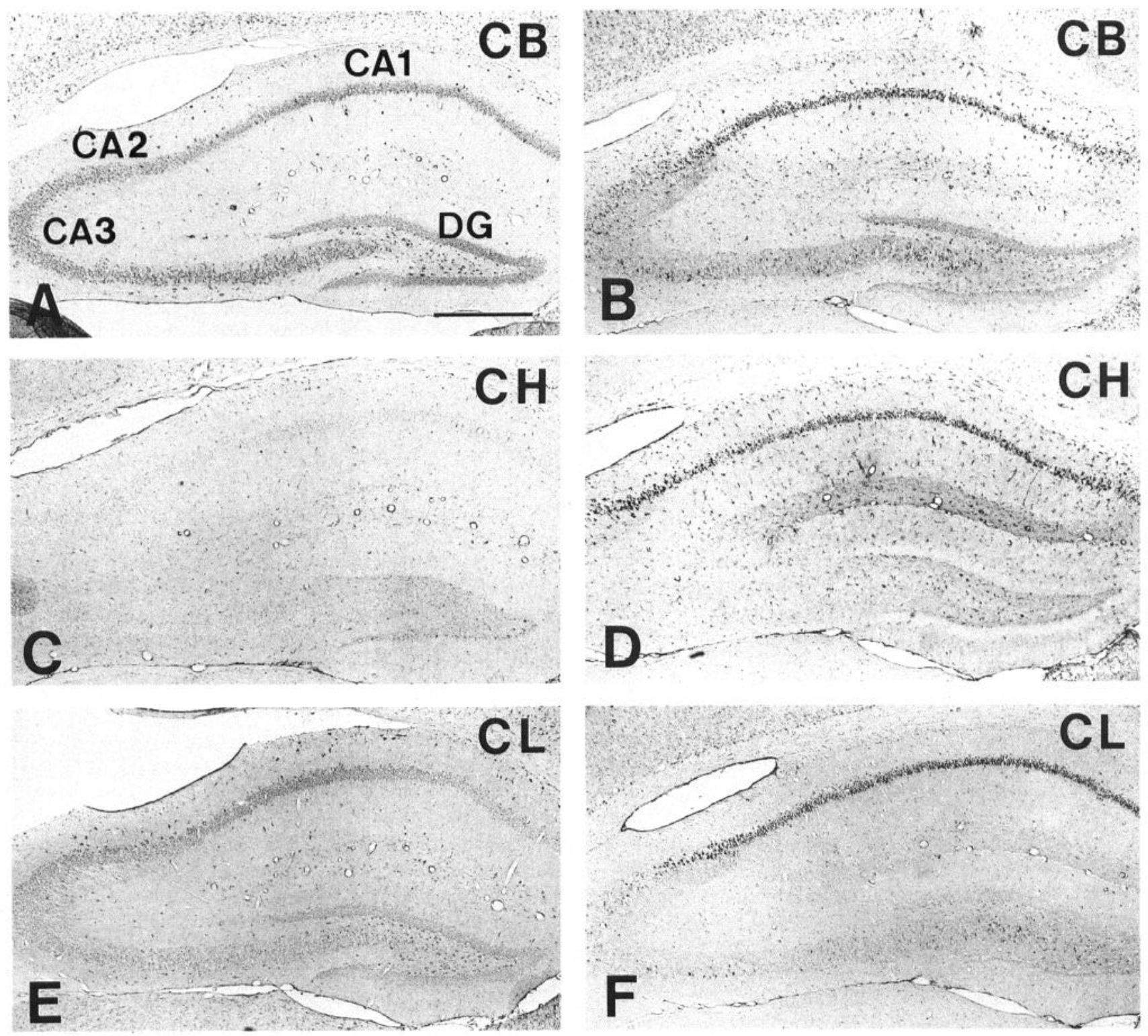

Figure 1. Changes in immunoreactivity for cathepsins $\mathrm{B}(\mathrm{CB}), \mathrm{H}(\mathrm{CH})$, and $\mathrm{L}(\mathrm{CL})$ in the hippocampus obtained from a sham-operated control gerbil brain $(A, C$, and $E)$, and from gerbil brains $3 \mathrm{~d}(B, D$, and $F)$ after the bilateral occlusion of the common carotid arteries for 5 min. The immunoreactivity for cathepsins B and $\mathrm{L}$ appears in the pyramidal and granular layers of the control hippocampus (CA1, CA2, and $C A 3)$ and dentate gyrus $(D G)$, respectively, while that for cathepsin $\mathrm{H}$ is detected in perivascular regions $(A, C$, and $E)$. Three days after ischemic insult, the immunoreactivity for these three enzymes increases mainly in the CAl pyramidal layer, but not in other regions $(B, D$, and $F)$. Note that the immunoreactivity for cathepsins $\mathrm{B}$ and $\mathrm{H}$ also increases in perivascular regions $(B$ and $D)$. Scale bar, $500 \mu \mathrm{m}$

\section{Antisera}

Rabbit antibodies to rat cathepsins $\mathrm{B}, \mathrm{H}$, and $\mathrm{L}$, were purified by affinity chromatography, as previously reported (Kominami et al., 1984, 1985; Bando et al., 1986). These antibodies were immunologically different from each other and showed no cross-reactivity (Kominami et al., 1984).

\section{Surgical procedures}

The bilateral common carotid arteries of gerbils under light ether anesthesia were exposed at the neck and were occluded with aneurysm clips for $5 \mathrm{~min}$. The clips were then released to resume the normal blood flow in the forebrain. Gerbils operated on without occluding the carotid arteries were used as sham operated controls.

Figure 2. Changes in immunoreactivity for cathepsins B $(\mathrm{CB}), \mathrm{H}(\mathrm{CH})$, and $\mathrm{L}(\mathrm{CL})$ in the CA1 pyramidal layer of the hippocampus obtained from a sham-operated control gerbil brain $(A, E$, and $G)$, and from gerbil brains $12 \mathrm{hr}(B), 24 \mathrm{hr}(C)$, and $3 \mathrm{~d}(D, F$, and $H)$ after the bilateral occlusion of the common carotid arteries for $5 \mathrm{~min}$. The immunoreactivity for cathepsin B in pyramidal neurons after ischemic insult progressively increases, compared with that in the control $(A-D)$. Particularly, coarse granular immunodeposits for these three enzymes are densely localized in the neurons $3 \mathrm{~d}$ after ischemic insults $(D, F$, and $H)$. Phagocytic microglia-like cells showing the intense immunoreactivity appear in the pyramidal cell layer (arrows). Scale bar, $20 \mu \mathrm{m}$. 


\section{CB}

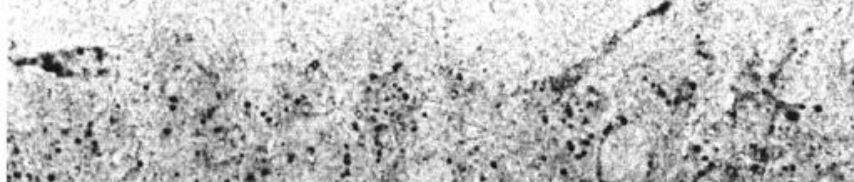

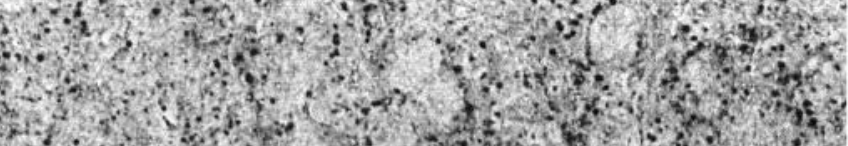

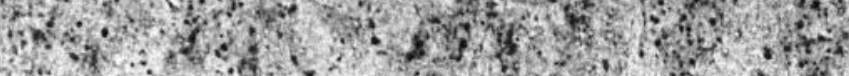

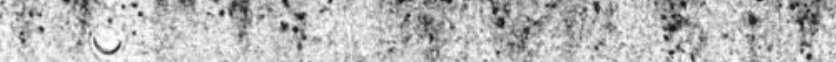
A

5ys?
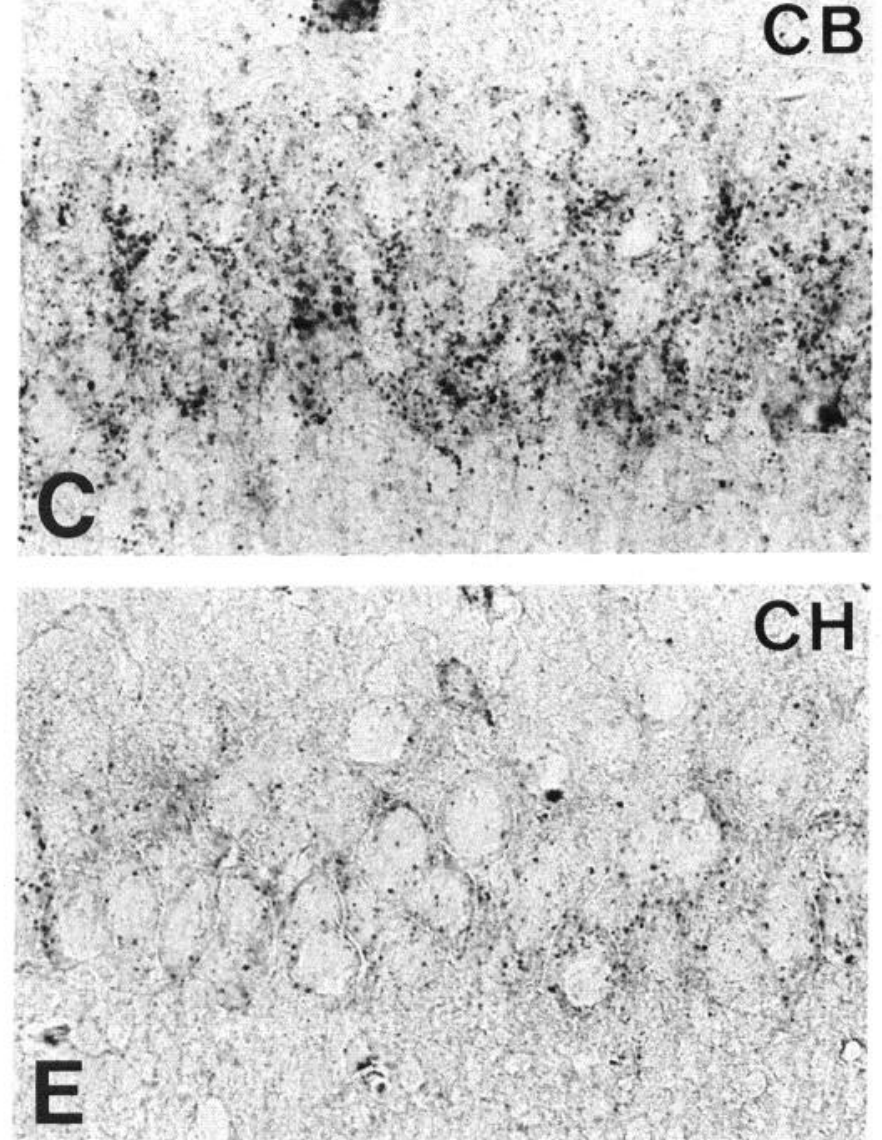

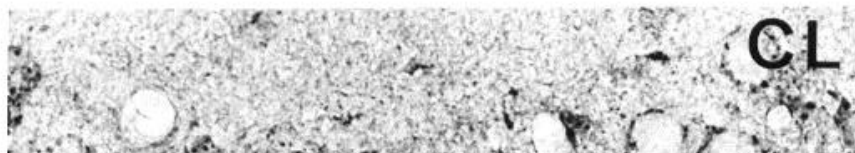

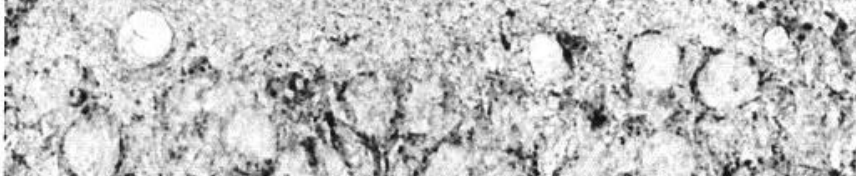

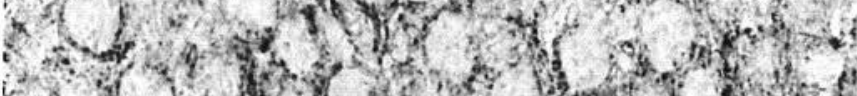

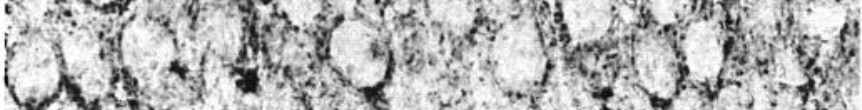

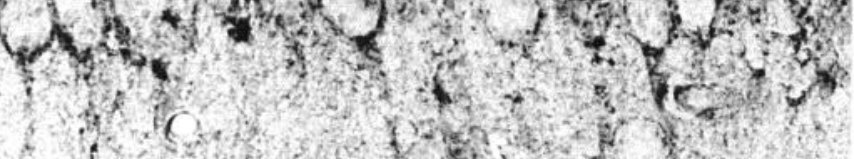

G

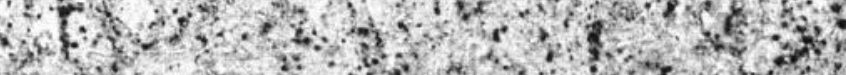

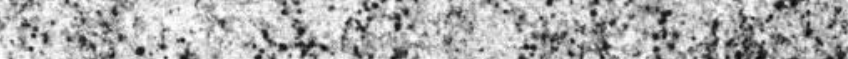

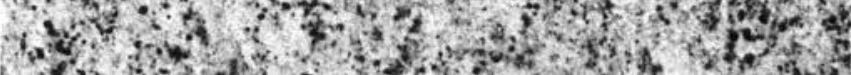

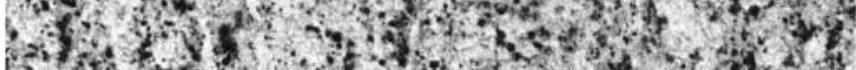

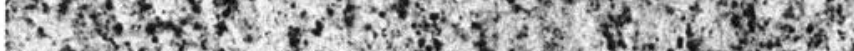

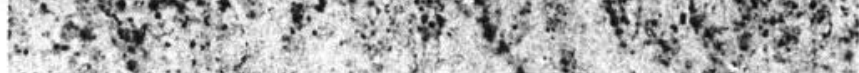
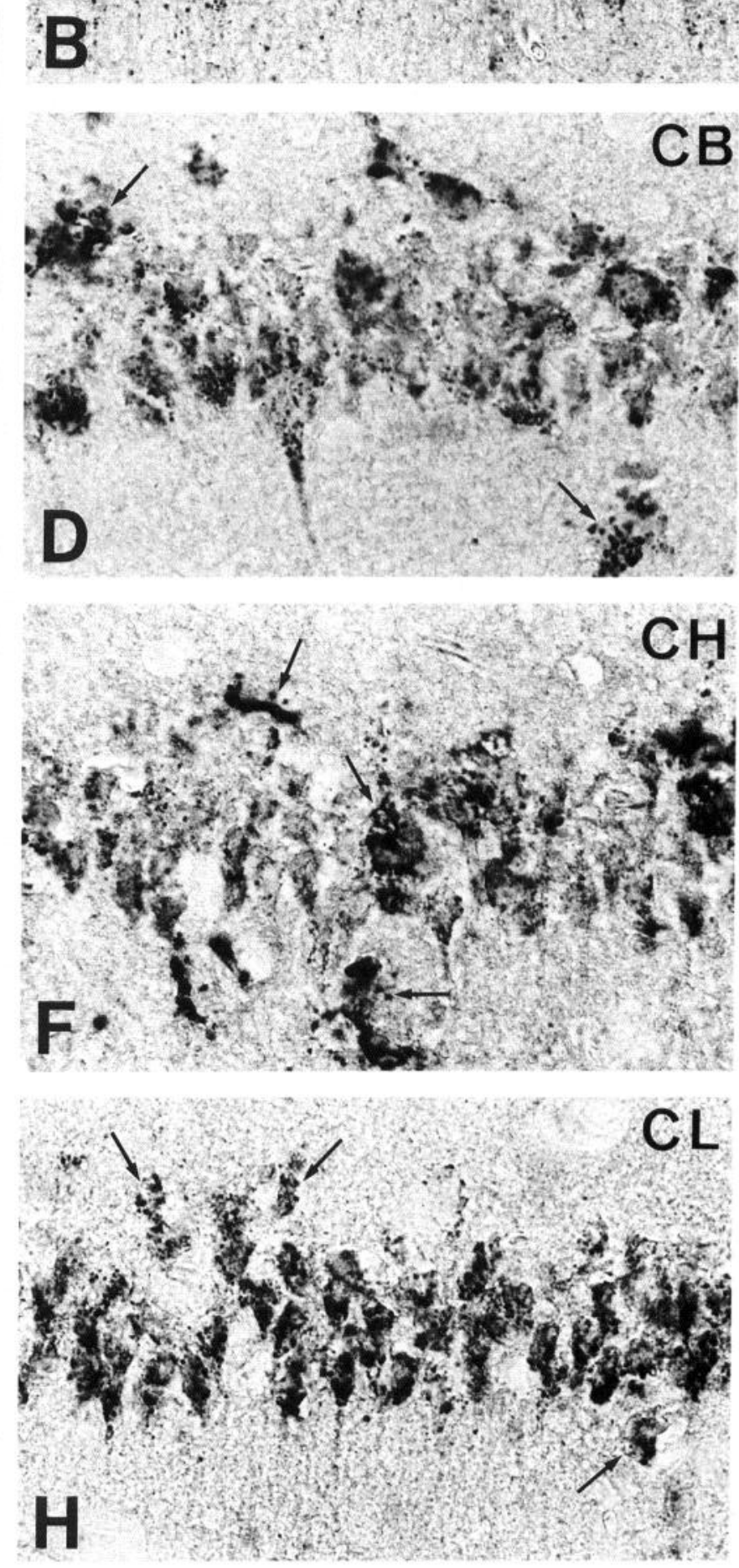

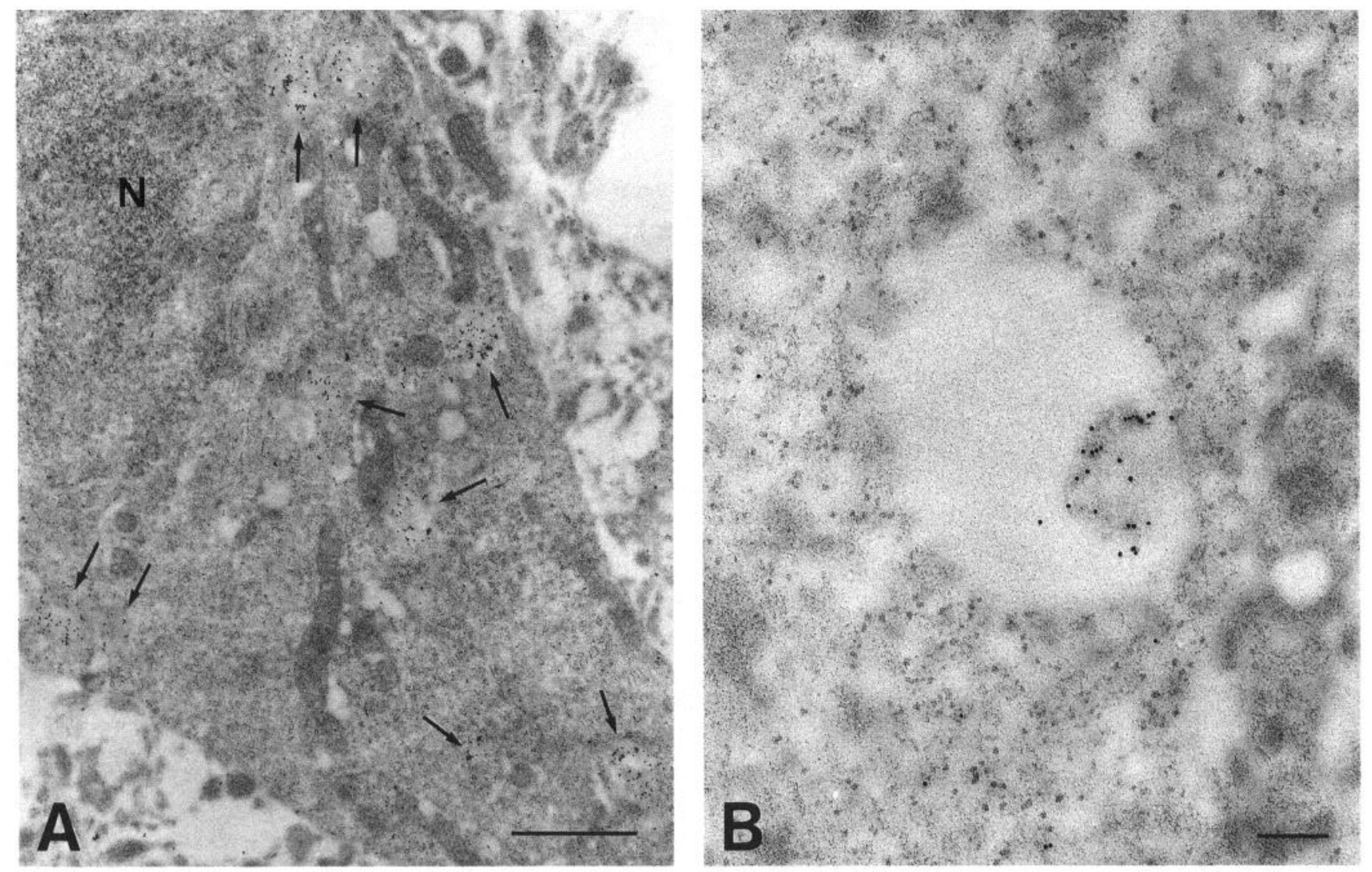

Figure 3. Immunocytochemical demonstration of cathepsin B in the CA1 pyramidal neurons $3 \mathrm{~d}$ after the bilateral occlusion of the common carotid arteries for $5 \mathrm{~min}$. A, Immunogold particles indicating cathepsin B are localized in numerous lysosomes of the neuron (arrows). B, A vacuolar structure containing amorphous structures, where the immunogold particles are localized, can be seen in the perikarya of the neuron. $N$, nucleus. Scale bars: $A, 1 \mu \mathrm{m} ; B, 0.2 \mu \mathrm{m}$.

\section{Samplings for immunohisto/cytochemistry and electron microscopy}

The sham-operated controls and ischemia-treated animals at $12 \mathrm{hr}$, and $1,2,3,4$, and $7 \mathrm{~d}$ after the resumption of the cerebral blood flow were deeply anesthetized with pentobarbital $(25 \mathrm{mg} / \mathrm{kg}$, i.p.) and fixed by cardiac perfusion with $4 \%$ paraformaldehyde buffered with $0.1 \mathrm{M}$ cacodylate- $\mathrm{HCl}$ buffer containing $4 \%$ sucrose, $\mathrm{pH} 7.2$, for light microscopic histochemistry and immunohistochemistry ( $n=5$ for each stage), with $4 \%$ paraformaldehyde- $0.1 \%$ glutaraldehyde buffered with the same buffer for electron microscopic immunocytochemistry ( $n=3$ for each stage), or $2 \%$ paraformaldehyde- $2 \%$ glutaraldehyde buffered with the same buffer for ordinal electron microscopy ( $n=3$ for each stage). The brains were then removed from each animal and cut coronally into about 3 mm-thick sections including the hippocampal area. For light microscopic histochemistry and immunohistochemistry, the samples were further immersed in the same fixative overnight at $4^{\circ} \mathrm{C}$ and embedded in OCT compound (Miles, Kankakee, IL) after cryoprotection with $15 \%$ and $30 \%$ sucrose solutions for cryosectioning. For electron microscopic immunocytochemistry, samples were dehydrated with graded alcohols and embedded in LR White at $-20^{\circ} \mathrm{C}$. For ordinal electron microscopy, samples were postfixed with $2 \%$ osmium tetroxide buffered with $0.1 \mathrm{M}$ cacodylate- $\mathrm{HCl}, \mathrm{pH} \mathrm{7.2,} \mathrm{dehydrated} \mathrm{with} \mathrm{graded} \mathrm{alcohols,} \mathrm{and} \mathrm{embed-}$ ded in Epon 812.

\section{Immunohisto/cytochemistry}

Light microscopy. Cryosections cut at $10 \mu \mathrm{m}$ with a cryostat (ReichertJung, Frigocut 2700, Germany) were immunostained using a method fully described elsewhere (Uchiyama et al., 1990). Briefly, they were treated with $0.3 \% \mathrm{H}_{2} \mathrm{O}_{2}$ in methanol for 30 min and incubated with $2 \%$ normal goat serum for $20 \mathrm{~min}$ at room temperature (RT). Then they were incubated with the following first antibodies for $3 \mathrm{~d}$ at $4^{\circ} \mathrm{C}$ : anti- cathepsin B $(5 \mu \mathrm{g} / \mathrm{ml})$, anti-cathepsin $\mathrm{H}(7 \mu \mathrm{g} / \mathrm{ml})$, and anti-cathepsin $\mathrm{L}(3 \mu \mathrm{g} / \mathrm{ml})$. Further incubations were performed with biotinylated goat anti-rabbit IgG (Histofine SAB-PO kit, Nichirei; Tokyo, Japan) and peroxidase-conjugated streptavidin (Nichirei) at RT for $20 \mathrm{~min}$. After each step, sections were rinsed thoroughly in $0.1 \mathrm{M}$ phosphate-buffered

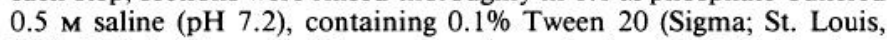
$\mathrm{MO}$ ). Staining for peroxidase was performed using $0.0125 \%$ diaminobenzidine (DAB) and $0.002 \% \mathrm{H}_{2} \mathrm{O}_{2}$ in $0.05 \mathrm{M}$ Tris- $\mathrm{HCl}$ buffer $(\mathrm{pH} 7.6)$ for $10 \mathrm{~min}$. Immunostained sections were in some cases counterstained with hematoxylin.

Electron microscopy. Thin sections were cut with an ultramicrotome (Ultracut N, Reichert-Nissei, Tokyo, Japan) and mounted on nickel grids. After incubation with 5\% normal goat serum (NGS) for $20 \mathrm{~min}$ at RT, the thin sections were incubated with anti-cathepsin B $(11 \mu \mathrm{g} /$ $\mathrm{ml})$ at $4^{\circ} \mathrm{C}$ overnight. Then they were treated with gold-labeled goat anti-rabbit IgG for $1 \mathrm{hr}$; the gold particles were coated and their sizes ( 8 or $15 \mathrm{~nm}$ in diameter) adjusted according to the method of Slot and Geuze (1985). Between each step, the grids were rinsed in $0.02 \mathrm{M}$ Tris$\mathrm{HCl}$ buffered $0.5 \mathrm{M} \mathrm{NaCl}, \mathrm{pH} 8.2$, containing $0.1 \%$ bovine serum albumin (BSA; Sigma). After the immunoreactions, sections were stained with a saturated aqueous solution of uranyl acetate and lead citrate and observed with a Hitachi H-7100 electron microscope.

Control experiments. Control cryosections were incubated with anticathepsins $\mathrm{B}, \mathrm{H}$, and $\mathrm{L}$ adsorbed by rat liver cathepsins $\mathrm{B}, \mathrm{H}$, and $\mathrm{L}$, respectively, or with a nonimmune rabbit serum diluted to $1: 1000$, followed by incubation with biotinylated goat anti-rabbit IgG and streptavidin-peroxidase. Some sections were directly incubated with the second antibody without any preceding incubation with the first antibodies. For immunoelectron microscopy, thin sections were incubated with the adsorbed antibody or with the nonimmune rabbit serum diluted to $1: 200$, followed by the gold-labeled second antibody. Some sections were directly incubated with the gold-labeled second antibody without pretreatment with the first antibody. 

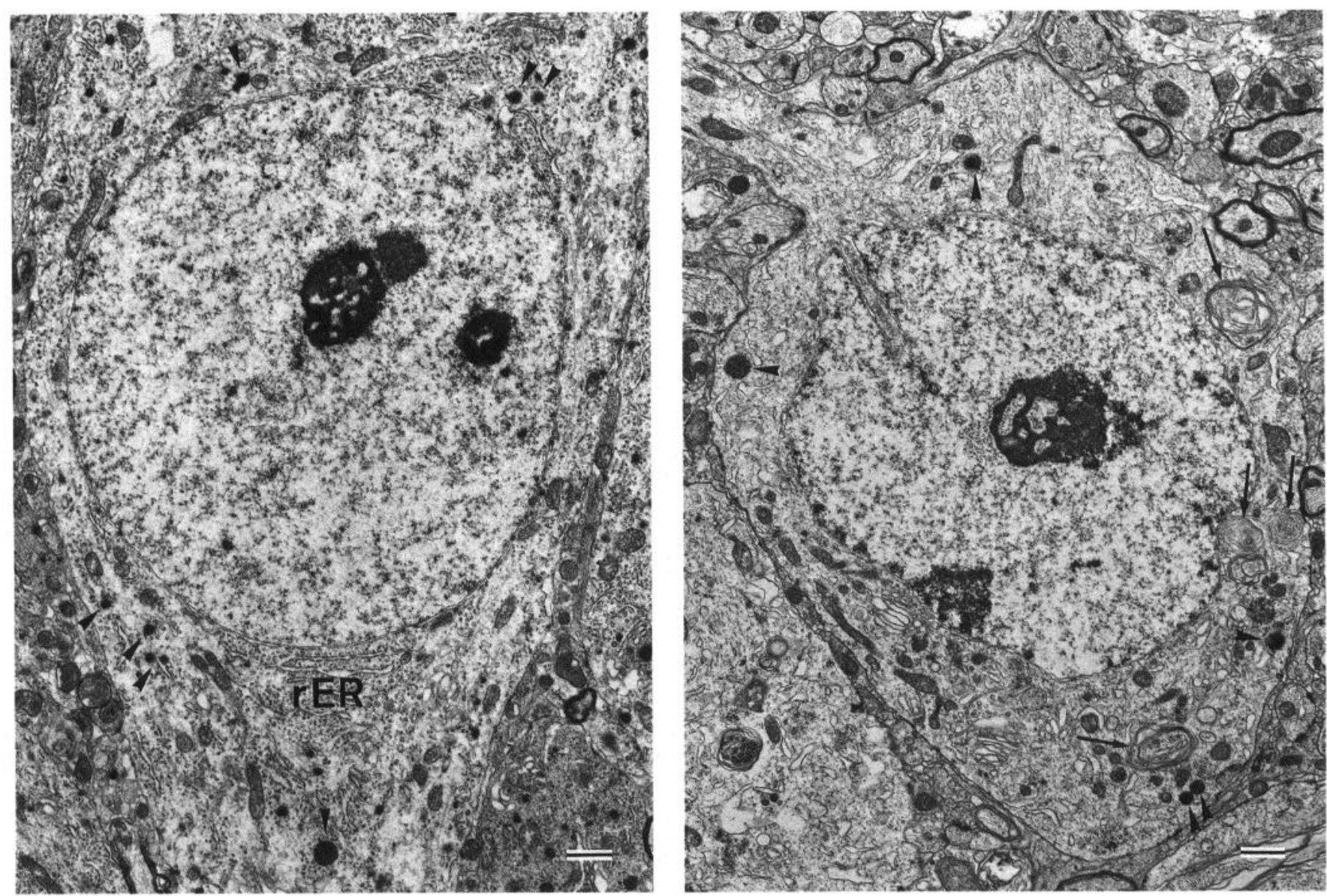

Figure 4. Electron micrographs of CA1 pyramidal neurons obtained from a sham-operated control gerbil brain $(A)$ and from that $3 \mathrm{~d}(B)$ after the bilateral occlusion of the common carotid arteries for $5 \mathrm{~min}$. The control neuron has a large round nucleus with the homogeneous karyoplasm and contains well-developed rough endoplasmic reticulum $(r E R)$ and several dense bodies (arrowheads) $A$, Three days after ischemic insult, the neuron has an indented nucleus with the homogeneous karyoplasm and contains dense bodies (arrowheads) and membrane-bounded vacuoles containing membranous structures and parts of the cytoplasm (arrows). B. Note that parallelly arranged rER disappears from the cytoplasm $3 \mathrm{~d}$ after ischemic insult, while mitochondrial profiles appear intact in both the control and ischemia-treated neurons. Scale bars, $1 \mu \mathrm{m}$.

All controls confirmed the specificities of immunoreactivity in light and electron microscopy.

Ordinal electron microscopy. Thin sections of the CA1 pyramidal layer embedded in Epon 812 were cut with an ultramicrotome. After stained with uranyl acetate and lead citrate, they were observed with an electron microscope.

Morphometry. To examine the volume densities of cathepsin B-immunopositive lysosomes, and dense bodies and autophagic vacuoles in the CAl pyramidal neurons of the control and ischemia-treated gerbil brains, the point-counting method was applied to the immunoelectron and ordinal electron micrographs (Watanabe and Uchiyama, 1988). Thirty CAl pyramidal fields of immunostained and ordinal sections obtained from the control group and ischemia-treated groups at $12 \mathrm{hr}$, $24 \mathrm{hr}$, and $3 \mathrm{~d}$ after ischemic insult were randomly chosen and photographed at the magnifications of $\times 5,000$ for immunoelectron microscopy and $\times 3,500$ for ordinal electron microscopy. The volume densities were analyzed at 10 times the original magnifications using a double-lattice system with a $1.5 \mathrm{~cm}$-spacing ( 235 test points). Statistical analysis was performed using Student's $t$ test.

DNA nick-end labeling. To detect DNA fragmentation in nuclei of the cells, the terminal deoxynucleotidyl transferase (TdT)-mediated dUTP-biotin nick-end labeling (TUNEL) reaction was applied to the cryosections according to the modified method of Gavrieli et al. (1992). Briefly, the cryosections were pretreated with or without $20 \mu \mathrm{g} / \mathrm{ml}$ proteinase K (Sigma) at RT for 15 min. After treatment with $0.3 \% \mathrm{H}_{2} \mathrm{O}_{2}$ in methanol for $30 \mathrm{~min}$, they were incubated with $100 \mathrm{U} / \mathrm{ml} \mathrm{TdT}$ and $10 \mathrm{nmol} / \mathrm{ml}$ biotinylated $16-2^{\prime}$-dUTP (Boehringer-Mannheim-Yamanouchi, Osaka, Japan) in TdT buffer (100 mm sodium cacodylate, pH $7.0,1 \mathrm{~mm}$ cobalt chloride, $50 \mu \mathrm{g} / \mathrm{ml}$ gelatin) in a humid atmosphere at $37^{\circ} \mathrm{C}$ for $60 \mathrm{~min}$. Further incubation with peroxidase-conjugated streptavidin or Texas red-conjugated avidin (Nichirei) was carried out for $60 \mathrm{~min}$ at RT. Staining for peroxidase was performed as described above.

Griffonia lectin histochemistry. To detect microglial cells, the cryosections were also stained with $20 \mu \mathrm{g} / \mathrm{ml}$ Griffonia simplicifolia lectinHRP or -FITC conjugate (Sigma) in $0.01 \mathrm{~m}$ phosphate-buffered $0.15 \mathrm{M}$ saline ( $\mathrm{pH} 7.2$ ), containing $0.1 \%$ Triton X-100 at RT for $2 \mathrm{hr}$ (Streit, 1990). Staining for peroxidase was performed as described above.

To examine the correlation of microglia with dying cells, double staining of Griffonia lectin and nick-end labeling of dUTP(Texas red labeling) was also carried out and viewed with a confocal laser scanning microscope (LSM-GB 200, Olympus, Tokyo, Japan).

Southern blotting. Hippocampal tissues including the CAl zone were dissected from gerbil brains of the sham-operated controls and of those 2,3 , and $4 \mathrm{~d}$ after ischemic insult under a binocular microscope $(n=$ 5 for each stage). Genomic DNA from each hippocampal tissue was prepared by a modification of the method of Sambrook et al. (1989). Each sample was subjected to electrophoresis on a $1.8 \%$ agarose gel and transferred to a nylon membrane (Sambrook et al., 1989). To detect the transferred DNA, the membrane was hybridized with ${ }^{32} \mathrm{P}$-labeled EcoRIdigested gerbil brain DNA. The membrane was then subjected to autoradiography.

\section{Results}

\section{Cytoplasmic changes}

Immunohisto/cytochemistry. In the sham-operated gerbil brains, immunoreactivity for cathepsins $\mathrm{B}, \mathrm{H}$, and $\mathrm{L}$ was detected in 

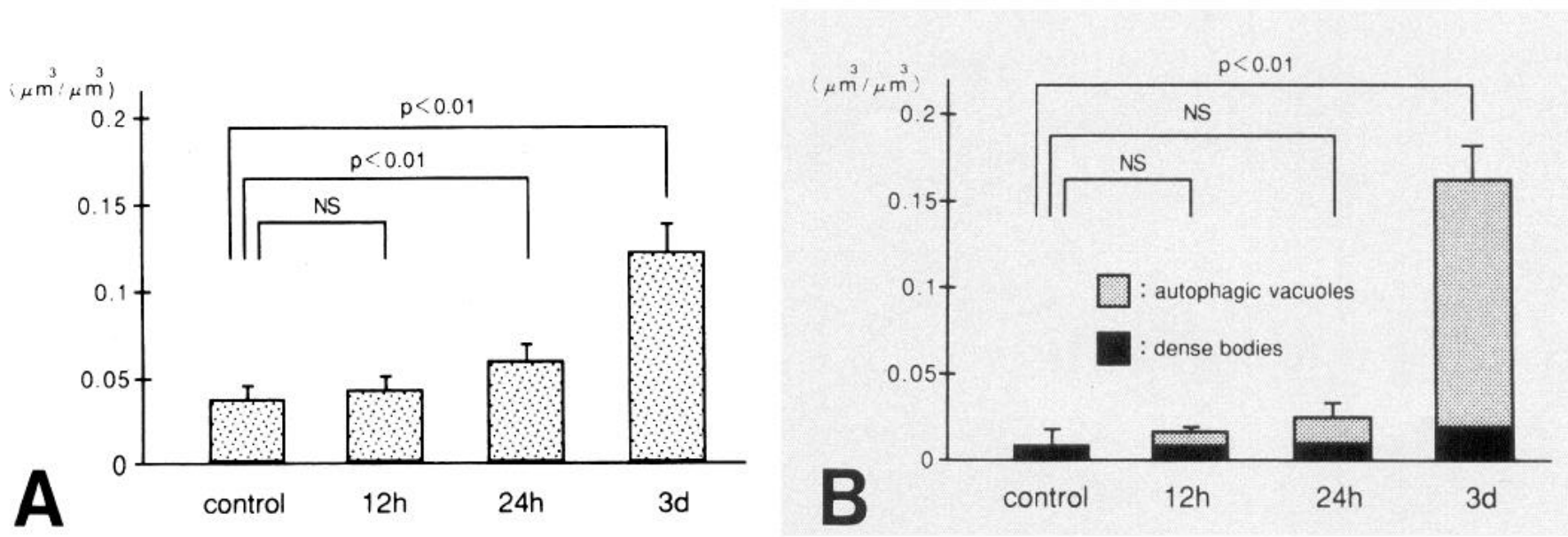

Figure 5. Changes in the volume densities $\left(\mu \mathrm{m}^{3} / \mu \mathrm{m}^{3}\right)$ of cathepsin B-immunopositive lysosomes $(A)$, and of dense bodies $(B)$ and autophagic vacuole-like structures $(B)$ in the CAl pyramidal neurons of the hippocampus obtained from a sham-operated control gerbil brain, and from gerbil brains $12 \mathrm{hr}, 24 \mathrm{hr}$, and $3 \mathrm{~d}$ after the bilateral occlusion of the common carotid arteries for $5 \mathrm{~min}$.

the $\mathrm{CA} 1, \mathrm{CA} 2$, and CA3 pyramidal layers of the hippocampus, and in the granular layer of the dentate gyrus, although that for cathepsin $\mathrm{H}$ was faint or weak (Fig. 1A,C,E). The immunoreactivity for these cysteine proteinases was also found in the perivascular regions, especially that for cathepsins $\mathrm{B}$ and $\mathrm{H}$. Three days after ischemic insult, the immunoreactivity for these enzymes was intensely elevated in the CA1 pyramidal layer, but not in other regions (Fig. $1 B, D, F$ ). The immunoreactivity for cathepsin $\mathrm{H}$ was also increased in the perivascular regions.

Granular immunodeposits for cathepsins $\mathrm{B}, \mathrm{H}$, and $\mathrm{L}$ were detected in the CA1 pyramidal neurons of the sham-operated control gerbil brains, but those for cathepsin $\mathrm{H}$ were less in number (Fig. 2A,E, $G$ ). The immunodeposits for these cysteine proteinases gradually increased and became coarse in the pyramidal neurons after ischemic insult (Fig. $2 B-D, F, H$ ). In particular, $3 \mathrm{~d}$ after ischemic insult, the CA1 pyramidal neurons, which became shrunken, were densely immunostained by anticathepsin $\mathrm{B}, \mathrm{H}$, or L (Fig. $2 D, F, H$ ). At this stage, microglial cells showing the immunoreactivity for these cysteine proteinases also appeared close to the CAl pyramidal neurons (Figs. $2 D, F, H ; 9 B)$.

By electron microscopy, immunogold particles indicating cathepsin B were localized in lysosomes of the neurons $3 \mathrm{~d}$ after ischemic insult (Fig. 3A,B). Large vacuoles containing dense amorphous materials, where immunogold particles showing cathepsin B were deposited, often appeared in the neurons at this stage (Fig. $3 B$ ).

Electron microscopy. As the immunoreactivity for cysteine proteinases increased in the CAl pyramidal neurons $3 \mathrm{~d}$ after ischemic insult, when the profiles of the neurons were shrunken, we examined the ultrastructure of the neurons at this stage. The control CA1 pyramidal neurons possessed well-developed rough endoplasmic reticulum (rER), numerous polysomes, and several dense bodies in the perikarya (Fig. $4 A$ ). Three days after isch- emic insult, profiles of rER and polysomes decreased from the perikarya of the neurons, whereas numerous dense bodies and membrane-bounded vacuoles containing membranous structures and parts of the cytoplasm, which seemed to be autophagic vacuoles, appeared in them (Fig. $4 B$ ). Profiles of mitochondria and the Golgi complexes appeared intact $3 \mathrm{~d}$ after ischemic insult.

To examine the correlation of cathepsin B-immunopositive lysosomes with dense bodies or autophagic vacuole-like structures appearing in the CAl neurons after ischemic insult, we analyzed the volume densities of these structures using immunostained and ordinal electron microscopic sections. As shown in Figure 5A, the density of cathepsin B-immunopositive lysosomes significantly increased in the neurons $3 \mathrm{~d}$ after ischemic insult and was about 3.4 times higher than that of the control. The density of dense bodies did not significantly change in the neurons after ischemic insult, but that of autophagic vacuole-like structures clearly increased $3 \mathrm{~d}$ after ischemic insult (Fig. 5B). Distinct increases in the volume densities of both cathepsin B-immunopositive lysosomes and autophagic vacuole-like structures $3 \mathrm{~d}$ after ischemic insult suggest that most of the cathepsin B-immunopositive lysosomes are autolysosomes corresponding to membrane-bounded (autophagic) vacuoles.

\section{Nuclear changes}

$T U N E L$ reaction. To detect nuclear changes in the CAl pyramidal neurons after ischemic insult, we examined the hippocampal tissue by the TUNEL reaction. Positive staining of the TUNEL reaction was weakly detected in nuclei of the CA1 pyramidal neurons $3 \mathrm{~d}$ after ischemic insult, but not in those obtained in the earlier stages nor in the sham-operated control brains (Fig. 6). Four days after ischemic insult, the positive staining in the neurons was not only localized in their cell bodies, but also in their dendrites forming the molecular layer (Fig.

Figure 6. TUNEL staining of the CA1 area of the hippocampus obtained from gerbil brains $2 \mathrm{~d}(A$ and $B), 3 \mathrm{~d}(C$ and $D), 4 \mathrm{~d}(E$ and $F)$, and 7 $\mathrm{d}(G$ and $H)$ after the bilateral occlusion of the common carotid arteries for 5 min. No staining is seen in the hippocampus $(A)$ and the CA1 pyramidal neurons $(B) 2 \mathrm{~d}$ after ischemic insult, whereas the positive staining specifically appears in the CA1 pyramidal layer $3 \mathrm{~d}(C), 4 \mathrm{~d}(E)$, and $7 \mathrm{~d}(G)$ after ischemic insult. Particularly, the positive staining is localized in the nuclei of the CAl pyramidal neurons $3 \mathrm{~d}$ after ischemic insult $(D)$, while it appears not only in their cell bodies but also in their dendritic processes forming the molecular layer on day 4 . Positively stained neurons decrease in number $7 \mathrm{~d}$ after ischemic insult $(H)$. Scale bars: $A, C, E$, and $F, 500 \mu \mathrm{m} ; B, D, F$, and $H, 20 \mu \mathrm{m}$. 

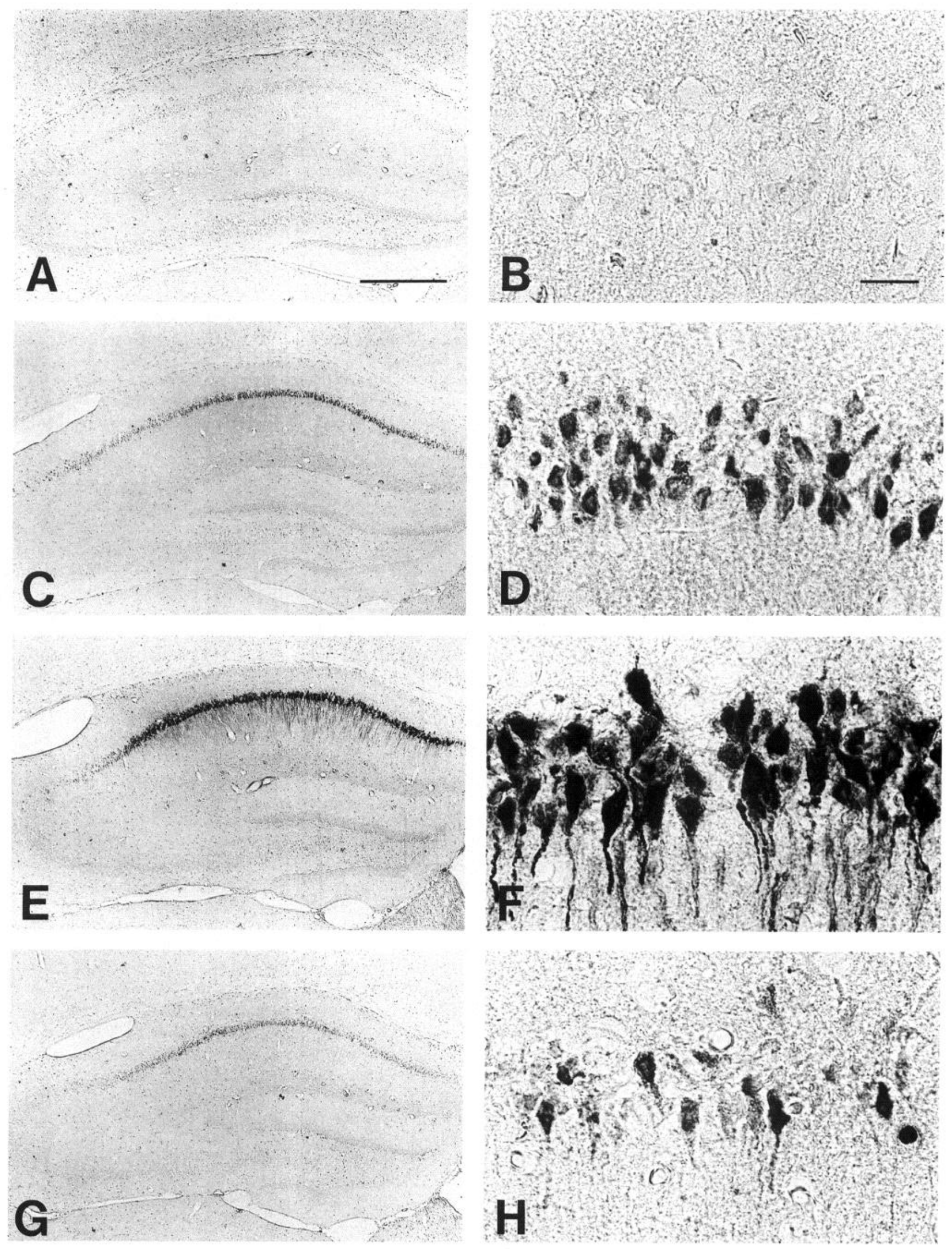


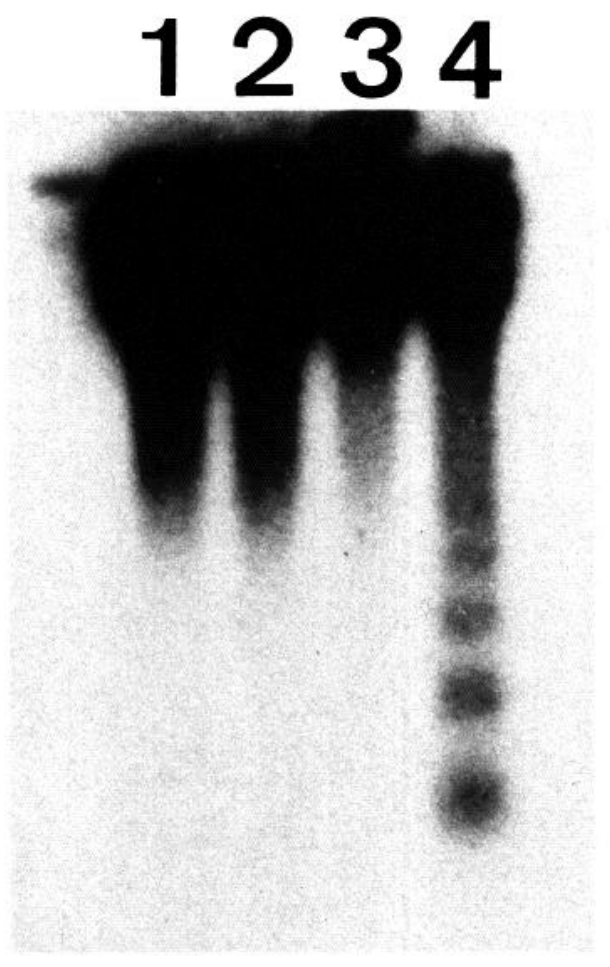

Figure 7. Southern blot analysis of hippocampal tissues containing the CA1 pyramidal layer obtained from a sham-operated control gerbil brain (lane 1), and gerbil brains $2 \mathrm{~d}$ (lane 2), $3 \mathrm{~d}$ (lane 3), and $4 \mathrm{~d}$ (lane 4) after the bilateral occlusion of the common carotid arteries for $5 \mathrm{~min}$. DNA fragmentation into oligonucleosomal fragments appears only in the tissue $4 \mathrm{~d}$ after ischemic insult.

$6 E, F)$. The CA1 pyramidal neurons, having the positively stained nuclei, were detected even $7 \mathrm{~d}$ after ischemic impact, although the number of the neurons distinctly decreased in the CA1 pyramidal layer (Fig. $6 G, H$ ).

Electron microscopy. Electron microscopically, the CA1 pyramidal neurons of the control brains had large round nuclei with a homogeneous electron density (Fig. $4 A$ ). Three days after ischemic insult, distinct karyoplasmic alterations in the nuclei of the CA1 neurons were not detected, but their nuclear profiles were often indented (Fig. $4 B$ ). Four days later, the CA1 neurons contained irregularly-shaped nuclei with dense chromatin masses (Fig. 7 $\mathrm{A}$ ), while apoptotic bodies containing distinct chromatin condensation were often found near microglial cells located in the CA1 pyramidal layer (Fig. $7 B$ ). Moreover, elongated nuclei of the neurons extended into the dendritic processes with a relatively high electron density, which seemed to correspond with the positive staining of the TUNEL reaction in the molecular layer (Fig. 7C). These nuclear changes occurred concomitantly with perikaryal condensation; numerous autophagic vacuoles and vacuolar structures (clear vacuoles) appeared in the shrunken perikarya of the neurons (Fig. 7A).

Southern blot analysis. Since the nuclear changes in the CA1 neurons suddenly occurred 3 or $4 \mathrm{~d}$ after ischemic insult, we examined genomic DNA in hippocampal tissue including the CAl region obtained from the control and ischemia-treated gerbil brains by Southern blotting. DNA fragmentation into oligonucleosomal fragments appeared only in the tissue $4 \mathrm{~d}$ after ischemic impact, but not in tissue at prior stages or in the control hippocampal tissue (Fig. 8).

\section{Microglial reaction}

We then examined the correlation of the dying neurons with microglial cells using Griffonia lectin histochemistry. Griffonia lectin-positive cells were not detected in the pyramidal layers of the hippocampus in the control brains, but they suddenly appeared in the CAl pyramidal layer $3 \mathrm{~d}$ after ischemic insult (Fig. 9A,B). Using a confocal laser scanning microscope, double staining demonstrated that the positively stained nuclei by the TUNEL reaction were phagocytosed by Griffonia lectin-positive microglial cells (Fig. 9C-E).

\section{Discussion}

In the present study, the following perikaryal as well as nuclear alterations were demonstrated in the CAl pyramidal neurons of gerbil hippocampus after brief ischemia: (1) perikaryal condensation with the formation of autophagic vacuoles (autolysosomes), (2) positive nick-end labeling of the nuclei, (3) dense chromatin masses in the nuclei and apoptotic bodies, (4) laddering of DNA, and (5) heterophagocytosis by microglial cells.

\section{Cytoplasmic alterations of the CA1 pyramidal neurons after ischemic insult}

By immunocytochemistry, cathepsins B and L are localized in the lysosomes of nerve cells and astrocytes in the rat CNS, while cathepsin $\mathrm{H}$ is only found in perivascular microglia-like cells (Bernstein et al., 1989, 1990; Taniguchi et al., 1993). The presence of these lysosomal cysteine proteinases in the CNS tissue has also been confirmed by enzyme immunoassay; the content of cathepsin B is high in the tissue, compared with that of cathepsins L and H (Kominami et al., 1985; Bando et al., 1986). In the present study, immunoreactivity for cathepsins B and L was clearly localized in nerve cells of the hippocampus of the sham-operated control gerbils, whereas that for cathepsin $\mathrm{H}$ was faintly detected in the CAl pyramidal neurons and densely present in perivascular microglia-like cells of the control brains. Therefore, it seems likely that the amount of the cathepsin $\mathrm{H}$ protein, even if expressed in nerve cells of the CNS tissue, is immunohistochemically very low.

The present study demonstrated that the immunoreactivity for cathepsin $\mathrm{H}$ appears in the CAl pyramidal neurons from the early stage after the ischemic insult, corresponding to the increase in the immunoreactivity for cathepsins B and L. It has been shown that pyramidal neurons in the gerbil hippocampus decrease uptake of radio-labeled L-tyrosine immediately after ischemic insult, but the uptake by the neurons mostly recovers within $24 \mathrm{hr}$ after ischemic impact, except for that by the CA1 pyramidal neurons (Thilmann et al., 1986). Lysosomal cysteine proteinases degrade old, unneeded proteins within lysosomes of mammalian cells into amino acids, which are reused for protein synthesis in the cells (Kirschke et al., 1980; Katunuma and Kominami, 1983). It is interesting that the decrease in the uptake of amino acids in pyramidal neurons of gerbil hippocampus after brief ischemia occurs concomitantly with the increase in the immunoreactivity for lysosomal cysteine proteinases including cathepsin $\mathrm{H}$.

Autophagy consisting of the sequestration of intracellular components and their degradation by lysosomal enzymes, usually occurs in normal cells to maintain cellular turnover, while it is known to greatly increase in cells under pathological conditions that cause cell dysfunction, such as hypoxia, ischemia, endotoxin shock, and metabolic inhibitors (Glaumann et al., 

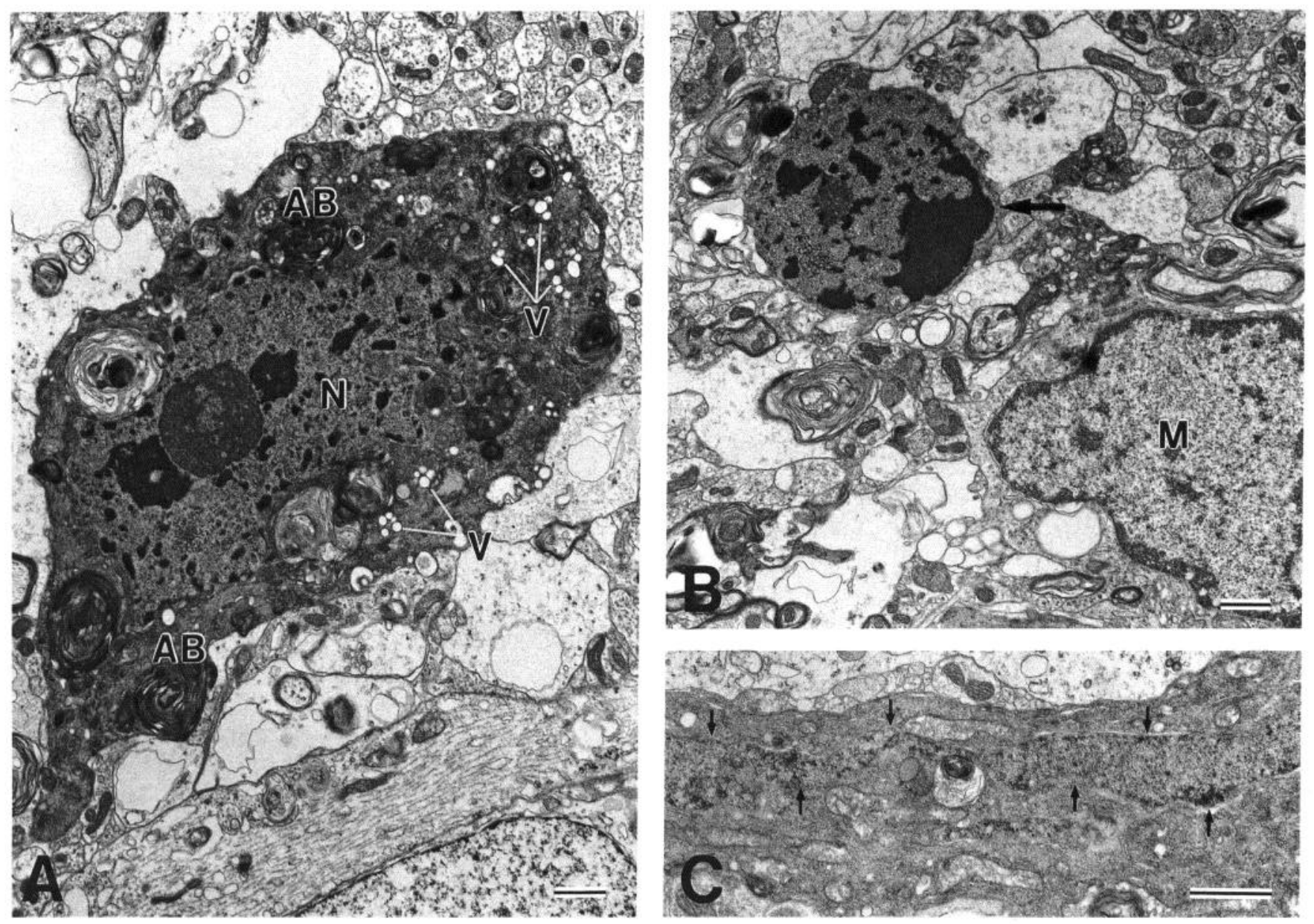

Figure 8. Electron micrographs of the CAl pyramidal neurons $4 \mathrm{~d}$ after the bilateral occlusion of the common carotid arteries for 5 min. A, A pyramidal neuron contains an irregularly shaped nucleus $(N)$ with condensed chromatin masses and shows karyoplasmic condensation with numerous vacuolar $(V)$ and autophagic body-like $(A B)$ structures. $B$, An apoptotic body (arrow) is seen near a microglial cell $(M)$. $C$, Parts of an elongated nucleus (arrows) is seen in a dendritic process with a relatively high electron density. Scale bars, $1 \mu \mathrm{m}$.

1981). By electron microscopy, we found that membranebounded vacuoles containing membranous structures and parts of the cytoplasm appeared in the CAl pyramidal neurons $3 \mathrm{~d}$ after ischemic insult, corresponding to increases in immunoreactivity for cathepsin $\mathrm{B}$ in lysosomes. The present morphometric study indicated that cathepsin B-immunopositive lysosomes are mostly autolysosomes or autophagic vacuoles corresponding to membrane-bounded vacuoles. These events suggest that the degradation of proteins in lysosomes of the CA1 pyramidal neurons is highly activated after the ischemic insult and that this process proceeds by forming autolysosomes.

In the process of autophagic alterations frequently occurring in dying cells, the role of the autophagy is believed to protect the cells from death (Clarke, 1990). That is, lysosomes in the CA1 pyramidal neurons early in the stage after ischemic insult may serve as a source of amino acids by actively degrading proteins. Concerning this point, the increases in the immunoreactivity for cysteine proteinases in the $\mathrm{CA} 1$ pyramidal neurons may play an important role in protecting them from further alterations. In contrast to the lysosomal reaction in the pyramidal neurons early in the stage after ischemic insult, cathepsin B-immunopositive autolysosomes or autophagic vacuoles rapidly increased $3 \mathrm{~d}$ later. In particular, the dying CA1 pyramidal neurons contained numerous autophagic vacuoles and vacuolar structures (clear vacuoles) $4 \mathrm{~d}$ after ischemic insult when perikaryal condensation occurred, although it remains unknown whether these autophagic vacuoles in the cells contain lysosomal enzymes. According to Clarke (1990), dying cells with autophagic vacuoles have been shown to undergo intense endocytosis, which can be thought of as inward blebbing and serves equally well to reduce the area of the plasma membranes. Therefore, it seems likely that the formation of autophagic vacuoles late in the stage after ischemic insult is closely associated with perikaryal condensation.

\section{Nuclear alterations of the CA1 pyramidal neurons after ischemic insult}

Gavrieli et al. (1992) have introduced the TUNEL reaction, by which nuclei of the dying cells associated with programmed cell death are positively stained. It is interesting that the nuclei of intestinal epithelial cells located in the tip of the villi are positively stained by the TUNEL reaction (Gavrieli et al., 1992), although no apoptotic cells are morphologically seen at the villi tips (Kerr et al., 1987). In the present study, we found the positive staining of the TUNEL reaction even in nuclei of the ischemia-damaged CA1 pyramidal neurons. Moreover, this positive reaction occurred in the nuclei prior to the morphological alterations with chromatin condensation. These results suggest 

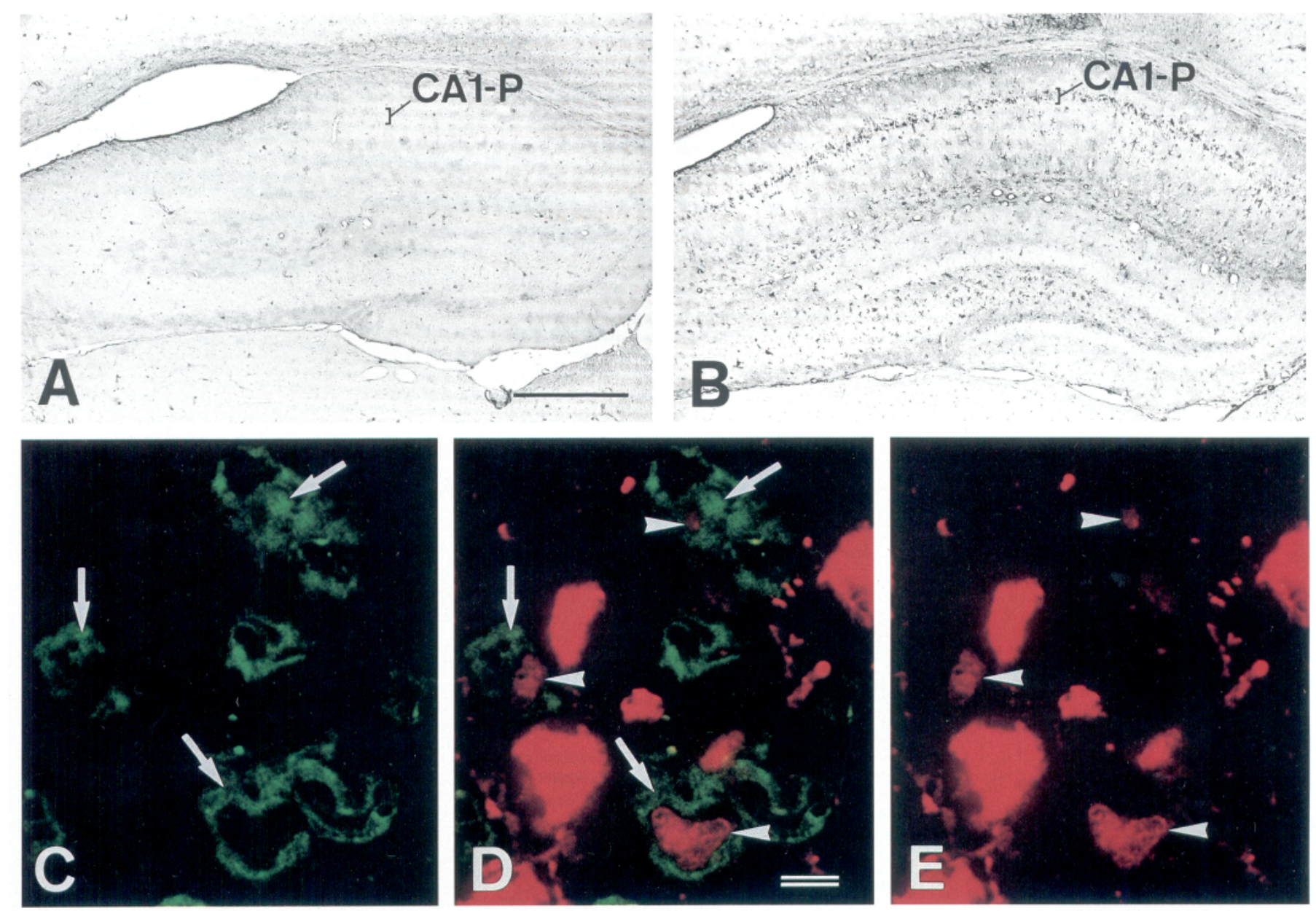

Figure 9. Demonstration of Griffonia lectin-positive microglial cells in the CAl area of gerbil hippocampus. $A$ and $B$, No positive staining of Griffonia lectin is seen in the CA1 pyramidal layer $(C A 1-P)$ of the control gerbil brain $(A)$, whereas its positive staining is detected in the layer 3 $\mathrm{d}$ after ischemic insult $(B)$. $C-E$, By a confocal laser scanning microscope, Griffonia lectin-positive microglial cells (green) (arrows) contain nuclei stained by the TUNEL reaction (red) (arrowheads) in the CAl pyramidal layer $4 \mathrm{~d}$ after ischemic insult (D). Griffonia lectin-positive cells are shown in $C$, while nuclei stained by the TUNEL reaction are displayed in $E$. Corresponding cells and nuclei are also indicated by arrows and arrowheads in $C$ and $E$. Scale bars: $A$ and $B, 500 \mu \mathrm{m} ; C-E, 5 \mu \mathrm{m}$.

that the TUNEL reaction more sensitively detects the nuclear changes with DNA fragmentation than morphological approaches do.

Four days after ischemic insult, the positive staining of the TUNEL reaction in nuclei of the CA1 pyramidal neurons occurred concomitantly with electron microscopic alterations: dense chromatin masses in their nuclei and apoptotic bodies with nuclei showing dense chromatin condensation in the pyramidal layer. Moreover, parts of nuclei spreading into dendrites of the CA1 neurons were detected by both the TUNEL reaction and electron microscopic analysis. By Southern blot analysis, we also found DNA fragmentation into oligonucleosomal fragments. These findings are consistent with morphological and biochemical criteria of apoptosis (Kerr et al., 1987; Clarke, 1990), indicating that the delayed neuronal death in the CAl pyramidal layer after brief ischemia is apoptosis.

As far as we observed, no nuclear change occurred in the CAl pyramidal neurons until $48 \mathrm{hr}$ after ischemic insult, suggesting that the delayed neuronal death requires 3 to $4 \mathrm{~d}$ after ischemic impact, if nuclear changes play a key role in cell death. Until the present, various morphological, physiological, and biochemical changes have been noted in the CAl pyramidal neurons after brief ischemia (Ito et al., 1975; Pulsinelli and Brierley, 1979; Kirino, 1982; Suzuki et al., 1983a,b; Kirino and Sano, 1984; Arai et al., 1986; Monmaur et al., 1986; Petito et al., 1987; Bonnekoh et al., 1990); however, there has been no accurate definition as to what reversible or irreversible alterations are in the neurons after brief ischemia. The in vitro study of neonatal sympathetic neurons has shown that the decrease in protein synthesis of the cultured neurons after nerve growth factor deprivation is insufficient to cause subsequent death, whereas DNA fragmentation of the neurons occurs close to the neuronal death (Deckwerth and Johnson, 1993). This implies that DNA fragmentation in the CA1 pyramidal neurons after brief ischemia is linked to irreversible alterations of the neurons.

\section{Microglial reaction}

Microglial cells have been shown to invade into the CAl pyramidal layer after ischemic insult (Kirino, 1982). We also found Griffonia lectin-positive microglial cells in the CAl pyramidal layer $3 \mathrm{~d}$ after ischemic insult, which phagocytosed nerve cell debris containing nuclei showing DNA fragmentation on day 4. Heterophagy has been shown to be prominent, when cells die by apoptosis (Kerr et al., 1987; Clarke, 1990). The results may 
indicate that the delayed neuronal death occurring in the CAl pyramidal layer after brief ischemia is apoptosis.

From the present results, we concluded that the delayed neuronal death occurring in the CAl pyramidal layer after brief ischemia is apoptosis. Considering prevention of neuronal death, it is important that initial disruption of $\mathrm{Ca}^{3+}$ homcostasis in the CAl pyramidal neurons by transient ischemia may cause neurotoxicity via mechanisms triggered by $\mathrm{Ca}^{2+}$ overload (Choi, 1988). In fact, in vivo and in vitro studies have indicated that $\mathrm{Ca}^{2+}$ channel blockers, glutamate receptor antagonists, or $\mathrm{Ca}^{2+}$ chelators prevent neuronal death from excitotoxic and ischemic neuronal injury (Rothman, 1984; Rothman and Olney, 1987; Sheardown et al., 1990; Buchan et al., 1991; Nellgård and Wieloch, 1992). In addition to these events, the present results displaying the apoptotic death of the CA1 neurons after brief ischemia may suggest further therapeutic interventions to prevent neuronal death.

\section{References}

Arai R, Passonneau JV, Lust WD (1986) Energy metabolism in delayed neuronal death of CAl neurons of the hippocampus following transient ischemia in the gerbil. Metab Brain Dis 1:263-278.

Bando Y, Kominami E, Katunuma N (1986) Purification and tissue distribution of rat cathepsin L. J Biochem 100:35-42.

Benveniste H, Drejer J, Schousboe A, Diemer NH (1984) Elevation of the extracellular concentrations of glutamate and aspartate in rat hippocampus during transient cerebral ischemia monitored by intracerebral microdialysis. J Neurochem 43:1369-1374.

Bernstein H-G, Sormunen R, Järvinen M, Kloss P, Kirschke H, Rinne A (1989) Cathepsin B immunoreactive neurons in rat brain. A combincd light and clcctron microscopic study. J Hirnforsch 30:313-317.

Bernstein H-G, Kirschke H, Roskoden T, Wiederanders B (1990) Distribution of cathepsin $\mathrm{L}$ in rat brain as revealed by immunohistochemistry. Acta Histochem Cytochem 23:203-207.

Bonnekoh P, Barbier A, Oschlies U, Hossmann K-A (1990) Selective vulnerability in the gerbil hippocampus: morphological changes after 5-min ischemia and long survival times. Acta Neuropathol (Berl) 80: $18-25$.

Brierley JB, Graham DL (1984) Hypoxia and vascular disorders of the central nervous system. In: Greenfield's neuropathology (Adams JH, Corsellis JAN, Duchen LW, eds), pp 125-207. New York: Wiley.

Buchen AM, Li H, Cho S, Pulsinelli WA (1991) Blockade of the AMPA receptor prevents CA1 hippocampal injury following severe but transient forebrain ischemia in adult rats. Neurosci Lett 132:255-258.

Choi DW (1988) Glutamate neurotoxicity and diseases of the nervous system. Neuron 1:623-634.

Clarke PGH (1990) Developmental cell death: morphological diversity and multiple mechanisms. Anat Embryol (Berl) 181:195-213.

Deckwerth TL, Johnson EM Jr (1993) Temporal analysis of events associated with programmed cell death (apoptosis) of sympathetic neurons deprived of nerve growth factor. J Cell Biol 123:1207-1222.

Gavrieli Y, Sherman Y, Ben-Sasson AJ (1992) Identification of programmed cell death in situ via specific labeling of nuclear DNA fragmentation. J Cell Biol 119:493-501.

Glaumann H, Ericsson LE, Marzella L (1981) Mechanisms of intralysosomal degradation with special reference to autophagocytosis and heterophagocytosis of cell organelles. Int Rev Cytol 73:149-182.

Ito U, Spatz M, Walker JT, Klatzo I (1975) Experimental cerebral ischemia in Mongolian gerbils. I. Light microscopic observations. Acta Neuropathol (Berl) 32:209-223.

Katunuma N, Kominami E (1983) Structures and functions of lysosomal thiol proteinases and their endogenous inhibitors. Curr Top Cell Regul 22:71-101.

Kerr JFR, Searle J, Harmon BV, Bishop CJ (1987) Apoptosis. In: Perspectives on mammalian cell death (Potten CS, ed), pp 93-128. New York: Oxford UP.

Kirino T (1982) Delayed neuronal death in the gerbil hippocampus following ischemia. Brain Res 239:57-69.

Kirino T, Sano K (1984a) Selective vulnerability in the gerbil hippocampus following transient ischemia. Acta Neuropathol (Berl) 62: 201-208.
Kirino T, Sano K (1984b) Fine structural nature of delayed neuronal death following ischemia in the gerbil hippocampus. Acta Neuropathol (Berl) 62:209-218.

Kirschke H, Langer J, Riemann S, Wiederanders B, Ansorge S, Bohley P (1980) Lysosomal cysteine proteinases. In: Ciba Foundation symposium 75, Protein degradation in health and disease (Evered D, Whelan J eds), pp 15-35. Amsterdam: Excerpta Medica.

Kominami E, Bando Y, Wakamatsu N, Katunuma N (1984) Different tissue distributions of two types of thiol proteinase inhibitors from rat liver and epidermis. J Biochem 96:1437-1442.

Kominami E, Tsukahara T, Bando Y, Katunuma N (1985) Distribution of cathepsins $\mathrm{B}$ and $\mathrm{H}$ in rat tissues and peripheral blood cells. J Biochem 98:87-93.

Monmaur P, Thomson MA, M'Harzi M (1986) Temporal changes in hippocampal theta activity following twenty minutes of forebrain ischemia in the chronic rat. Brain Res 378:262-273.

Nellgård B, Wieloch T (1992) Postischemic blockade of AMPA but not NMDA receptors mitigates neuronal damage in the rat brain following transient severe cerebral ischemia. J Cereb Blood Flow Metab 12:2-12.

Petito CK, Feldmann E, Pulsinelli WA, Plum F (1987) Delayed hippocampal damage in human following cardiorespiratory arrest. Neurology 37:1281-1286.

Pulsinelli WA, Brierley JB (1979) A new model of bilatcral hemispheric ischemia in the unanesthetized rat. Stroke 10:267-272.

Rothman SM (1984) Synaptic release of excitatory amino acid neurotransmitter mediates anoxic neuronal death. J Neurosci 4:18841891.

Rothman SM, Olney JW (1987) Excitotoxicity and the NMDA receptor. Trends Neurosci 10:299-302.

Sambrook J, Fritsch EF, Maniatis T (1989) Molecular cloning: a laboratory manual, $2 d$ ed. Cold Spring Harbor, NY: Cold Spring Harbor Laboratory.

Sheardown MJ, Nielsen EØ, Hansen AJ, Jacobsen P, Honoré T (1990) 2,3-Dihydroxy-6-nitro-7-sulfamoyl-benzo(F)quinoxaline: a neuroprotectant for cerebral ischemia. Science 27:571-574.

Slot JW, Geuze HJ (1985) A new method of preparing gold probes for multiplc-labeling cytochemistry. Eur J Cell Biol 38:87-93.

Streit WJ (1990) An improved staining method for rat microglial cells using the lectin from Griffonia simplicifolia (GSA I-B4). J Histochem Cytochem 38:1683-1687.

Suzuki R, Yamaguchi T, Kirino T, Orzi F, Klatzo I (1983a) The effects of 5-minutes ischemia in Mongolian gerbils. I. Blood-brain barrier, cerebral blood flow, and local cerebral glucose utilization changes. Acta Neuropathol (Berl) 60:207-216.

Suzuki R, Yamaguchi T, Li CL, Klatzo I (1983b) The effects of 5 -minutes ischemia in Mongolian gerbils. II. Changes of spontaneous neuronal activity in cerebral cortex and $\mathrm{CA} 1$ sector of hippocampus. Acta Neuropathol (Berl) 60:217-222.

Taniguchi K, Tomita M, Kominami E, Uchiyama Y (1993) Cysteine proteinases in rat dorsal root ganglion and spinal cord, with special reference to the co-localization of these enzymes with calcitonin generelated peptide (CGRP) in lysosomes. Brain Res 601:143-153.

Thilmann R, Xie Y, Kleihues P, Kiessling M (1986) Persistent inhibition of protein synthesis precede delayed neuronal death in postischemic gerbil hippocampus. Acta Neuropathol (Berl) 71:88-93.

Tymianski M, Wallace MC, Spigelman I, Uno M, Carlen PL, Tator $\mathrm{CH}$, Charlton MP (1993) Cell-permeant $\mathrm{Ca}^{2+}$ chelators reduce early excitotoxic and ischemic neuronal injury in vitro and in vivo. Neuron $11: 221-235$.

Uchiyama $Y$, Watanabe $T$, Watanabe $M$, Ishii $Y$, Matsuba $H$, Waguri $S$, Kominami E (1989) Localization of cathepsins B, H, and $L$ in follicular cells of the rat thyroid gland. J Histochem Cytochem 37: 691-696.

Uchiyama $Y$, Nakajima M, Muno D, Watanabe T, Ishii Y, Waguri S, Sato N, Kominami E (1990) Immunocytochemical localization of cathepsins $\mathrm{B}$ and $\mathrm{H}$ in corticotrophs and melanotrophs of rat pituitary gland. J Histochem Cytochem 38:633-639.

Watanabe M, Uchiyama $Y$ (1988) Twenty-four hour variations in subcellular stı uctures of rat pancreatic islet B-, A- and D-cells, and of portal plasma glucose and insulin levels. Cell Tissue Res 253:337345. 